\title{
Added Value of Barki Wool Comparing to Merino for Woven Fabrics Properties
}

\author{
Gad-Allah AAI ${ }^{1}$, Al-Betar EM ${ }^{1}$ and Marwa A Ali ${ }^{2 *}$ \\ ${ }^{1}$ Wool production and technology Department, Animal and poultry production division, Desert Research Center, Egypt \\ ${ }^{2}$ Spinning and Weaving Engineering, Dept. Textile Industries Research Division, National Research Centre, Egypt
}

*Corresponding author: Marwa Atif Ali, Spinning and Weaving Engineering Department, Textile Industries Research Division, National Research Centre, Cairo, Egypt.

\author{
Received Date: May 27, 2020
}

Published Date: June 05, 2020

\begin{abstract}
Barki wool as a coarse wool is considered one of the existing materials in the Egyptian environment, which its different properties have not exploited properly yet, especially the mechanical. Where only the defects of its own are seen like fiber wrinkling, harshness and irregularity of micron, so its usage only limited on the handmade carpet or the weft yarns that used in the mechanical floor coverings. The research is aiming to study the difference properties between Barki wool as a local material and Merino wool as an imported material, improving properties and utilizing of local wool properties to make multi-uses fabrics which different from its usual uses. Barki and Merino wool blended with woolen polyester, two ratios were used of Barki/polyester (30:70)\% and (45:55)\% to produce samples, and one ratio was used of Merino/polyester (45:55)\% for comparing, all produced samples were weaved by twill $2 / 2$ weave structure. The produced samples were evaluated by mechanical and physical properties, statistically was analyzed by variance analysis (ANOVA) with General Linear Model (GLM) of SAS and differences between means were tested using Duncan's multiple range test. It was concluded that the blending ratios of wool and polyester to produce the samples significantly affected on all physical and mechanical properties for samples. In addition, the values of mechanical properties of samples produced from Barki wool increased, while the values of the physical properties of samples produced from Merino wool increased.
\end{abstract}

Keywords: Coarse; Barki wool; Woven fabric; Merino wool; Mechanical properties

\section{Introduction}

In Egypt, there is a significant increase in the total amount of wool produced during the last 10 years from 4530 tons in 2003 to 12500 tons in 2013 [1]. Barki sheep breed is one of the three major sheep breeds in Egypt. Its predominant distribution is the northwestern coastal zone (NWCZ) of Egypt [2]. Barki sheep has a white body and a brown or black head, the color of the head may extend to cover the neck; a white color of head may be rarely. Its legs are usually colored or spotted [3]. Barki wool is processed into low quality woolens and blended with other types of wool [4].

Barki fleece wool was subdivided into three grades; $13.4 \%$ fine, $72 \%$ medium and $14.6 \%$ strong. Grades of wool subjectively are varying according to the fiber handlings harshness and fineness that lead to improved quality during industrial processes. However, it was suggested the fine wool grade to produce apparel and knitted yarns. Mostly, the difference of longitudinal micron of wool fibers is the main factor to reject the local wool by manufacturers, therefore, most of their products are used by the lower class of society or desert residents $[5,6]$.

Generally, Wool fiber has a good thermal insulation either in state of wet or with moisture regains at a certain temperature and relative humidity. Whereas, it is absorbing more moisture than cotton, before becoming saturated, and causing the sensation of wet cling on the skin [7].

Many times, it was needed to mix between different materials to obtain the specific properties. Blended yarn has several types of fibers (two or more constituents) blended, which is completely 
unique [8]. The blended spinning technique depended on the fiber length (staple length) of material in case of natural material such as cotton and wool [9].

Polyester is one of the most common man-made fibers; it is cheap and has easy-care and excellent washing properties and wearing appearance. So, it was used in textile industries to improve the durability and uniformity. When polyester is proposed to contact with skin in a cloth, it is usually treated to improve its wicking ability. Blending wool fiber and polyester fiber had improved moisture management properties compared to fabrics in wool fiber without blending [7]. Adding the polyester fibers to coarse and fine Barki wool grades led to improve yarn strength properties [10].

Merino Sheep is one of the oldest and strongest breeds during the summer and freezing winter around the world. Now, it was breed mainly in New Zealand and Australia. Merino Sheep produces the finest and smoothest fibers comparing with all wools; it is the perfect performance fabric for the 21st Century. The Merino wool fabrics were produced with different weights began from $150 \mathrm{~g} / \mathrm{m} 2$ for very light fabrics to $250 \mathrm{~g} / \mathrm{m} 2$ for heavy fabrics. The garment wool fabric was used the weight between 140- $195 \mathrm{~g} / \mathrm{m} 2$. Merino wool characterized with light weight, odor buildup resistance, easy washable, quick drying, durability, long lasting and give UV protection when untreated by chemical processes reach to about $50 \%$ comparing other materials $[11,12]$.

Polyester wool blended fabric leads to pilling tendency, this

Table 1: Characterization of used materials

\begin{tabular}{|c|c|c|c|}
\hline Properties & Barki Wool & Merino350 $^{\circledR}$ Wool & Woolen Polyester \\
\hline Color & raw & raw & white \\
\hline Fiber length & $60-70 \mathrm{~mm}$ & $60-70 \mathrm{~mm}$ & $80 \mathrm{~mm}$ \\
\hline Denier of fiber $(\mu)$ & 28.8 & 21.5 & 17.5 \\
\hline
\end{tabular}

Merino350® wool is an imported textile material that used in the clothing industry, it was used the medium grade of Merino. Woolen polyester is a common material used when blended with wool. The two materials were brought from Misr Spinning and Weaving Company, Al-Mahalla Al-Kubra, Egypt.

\section{Methods}

Two samples of woven fabrics were produced from Barki wool blended with woolen polyester in the spinning step with different ratios as (45:55) \% and (30:70)\%. One sample produced from Marino wool blended with woolen polyester by (45:55)\% ratio, all property related to different parameters of textile like fiber properties, yarn \& fabric structure, finishing processes and blended ratio between the materials. The finer fibers have a lower pilling than coarser fibers. In addition to, the plain-woven structure has less percentage of pills comparing to twill and satin woven structures, which due to the higher intersections for plain structure [13].

The research aims to study the properties of produced multiuses fabrics with coarse Egyptian Barki wool that blended with woolen polyester, other than floor coverings. In order to improve the added value for its properties and higher the economic value for local wool. Moreover, the quality of produced Barki/polyester fabrics was evaluated by comparing with the most used and widespread wool Merino/polyester with similar to one of the two ratios used for Barki/polyester and the same weave structure for all produced samples.

\section{Materials and Methods}

\section{Materials}

Barki wool was collected from the Mariout Research Station, belonging to the Desert Research Center, Egypt, during the shearing season 2015. The wool was graded subjectively by visual assessment on a sorting table to separate the fine wool fleeces. Then, they were carried out the scouring and carding processes for fine Barki wool fleeces, Barki wool was used in this search classified as fine wool as shown in Table 1.

Table 2: Specification of produced samples.

\begin{tabular}{|c|c|c|c|c|c|c|c|c|c|}
\hline SC. & Material & $\begin{array}{c}\text { Ratio } \\
(\%)\end{array}$ & $\begin{array}{c}\text { Warp Co. } \\
\text { (Ne) }\end{array}$ & $\begin{array}{l}\text { Weft Co. } \\
\text { (Ne) }\end{array}$ & $\begin{array}{l}\text { Picks/ } \\
\text { inch }\end{array}$ & $\begin{array}{l}\text { Ends/ } \\
\text { inch }\end{array}$ & C.F & Weight $\left(\mathrm{g} / \mathrm{m}^{2}\right)$ & Thick (mm) \\
\hline Mer/PSF & Merino/polyester & $45: 55$ & $50 / 2$ & $50 / 2$ & 46 & 46 & 9.2 & 160 & 0.45 \\
\hline Bri/PSF1 & Barki / polyester & $45: 55$ & $24 / 2$ & 12 & 38 & 32 & 10.12 & 311 & 0.7 \\
\hline Bri/PSF2 & & $30: 70$ & $24 / 2$ & 12 & 38 & 32 & 10.12 & 290 & 0.65 \\
\hline \multicolumn{10}{|c|}{ SC.: Sample Code } \\
\hline
\end{tabular}


The difference between yarn counts used for each type of wool, due to the morphological properties of each one, which results difference densities for both warp and wefts yarns in the certain unit, to achieve an acceptable cover factor, as well as for weight and thickness values. Also, it was noted that the cover factor is much closed for all produced samples as shown in Figure 1.
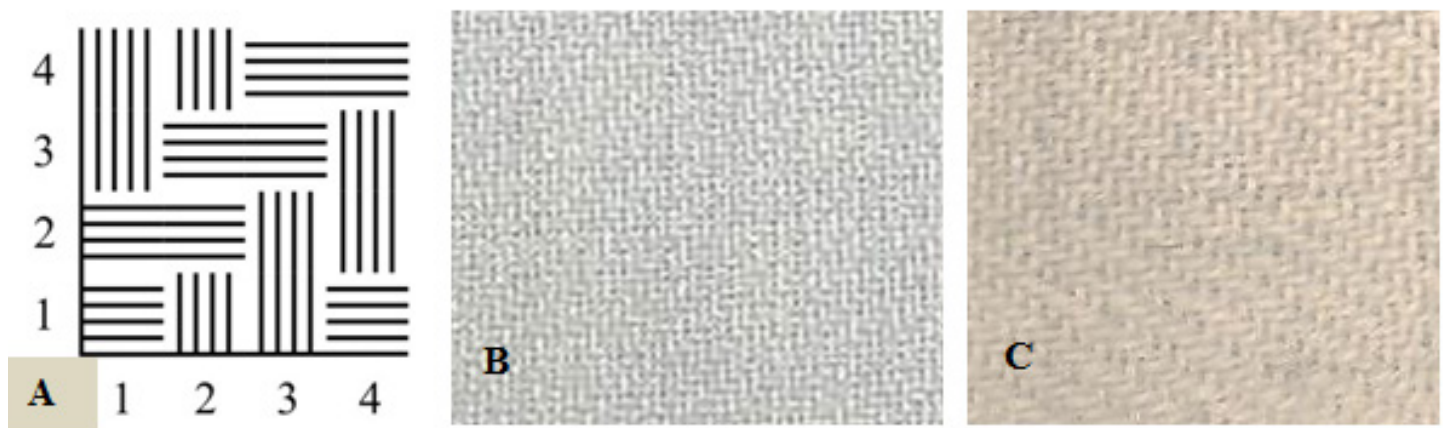

Figure 1: Inversed twill 2/2 structure of produced samples from various wool; A: Inversed twill 2/2, B: Merino/polyester fabric and C: Barki/ polyester fabric.

\section{Evaluation tests}

All produced samples were evaluated by mechanical and physical properties; they were put in the standard atmospheric conditions for 24 hours before testing according to ISO-139.The tests which carried out on produced samples as follows; tensile strength \&elongation of fabrics according to ASTM-D5035-11, stiffness resistance according to ASTM-D1388-96,abrasion resistance by loss in weight indication according to ASTM-D4158-08, shrinkage of fabric AATCC 135, pilling test fabric was estimated by ICI pill box tester, fabric thickness according to ASTM-D1777-96, air permeability according to ASTM-D737-96, water permeability was measured according to ASTM-D 461, and electrostatic charges were determined according to ASTM-D 4238 and the test was performed using FMX-003TM Electrostatic field meter, there are three grades for evaluating the static electricity on the surface of various materials as shown in Table 3.

Table 3: Frictional-charge classification [14]

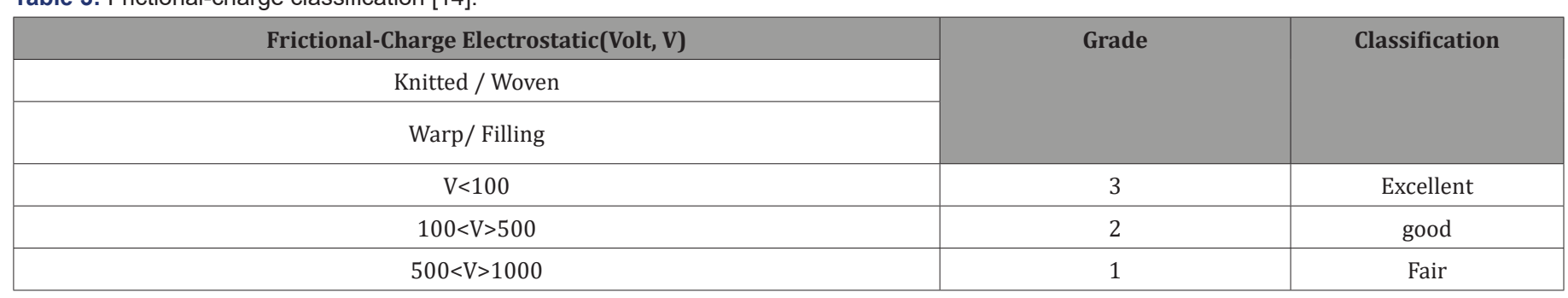

\section{Statistical analysis}

The test results were statistically analyzed by analysis of variance (ANOVA) with General Linear Model (GLM) of SAS (2001) [15] and differences between means were tested using Duncan's multiple range test [16]. The significance level was set at $\mathrm{P}=0.05$ and $\mathrm{P}=0.01$. In addition to, it was pointed to order of the bestproduced samples by radar chart area.

\section{Results and Discussion}

The various results were presented for the mechanical and physical properties of the produced samples, and the difference between the properties of wool types used were cleared.

\section{Effect the ratio and types of wool on the mechanical and physical properties}

Tensile strength and elongation properties: Figure 2 shows that the tensile strength for warp and weft yarn direction, the samples that produced with Barki/polyester gave high value of tensile strength comparing with the sample produced from Merino/polyester, especially in warp direction that affected with the weft yarns. Also, the increasing of polyester ratio in the produced samples led to increase in the value of strength, this is due to the tenacity of polyester material and this result is agreed with previous investigations $[17,18]$, and the density of warp yarns in these two samples also affected on them as a high strength. It was reported by Helal, et al. that an increase of polyester ratio from $25 \%$ to $35 \%$ or $40 \%$ led to a slight increase in yarn elongation. However, differences were not significant [10].

The elongation is varying between the produced samples as shown in Figure 3. The samples produced with Barki/polyester achieved higher elongation value than the sample produce Merino/ polyester especially in weft direction; this is may be due to the yarn count of Barki wool yarns and high fiber diameter of its grades. 


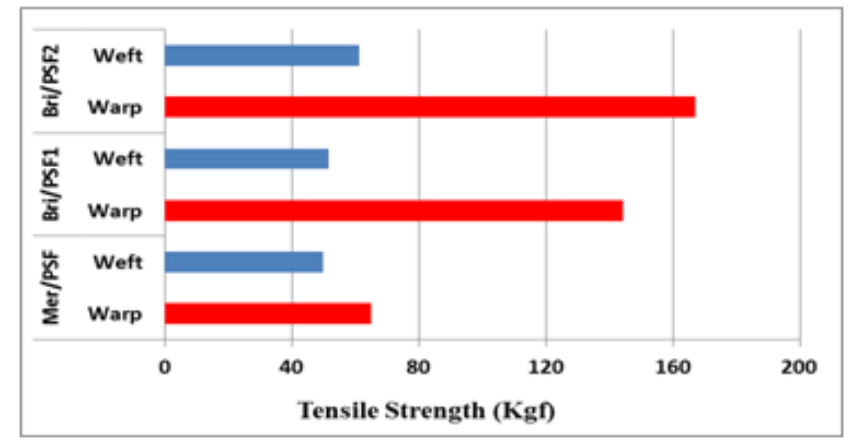

Figure 2: Warp and weft tensile strength values of different produced samples.

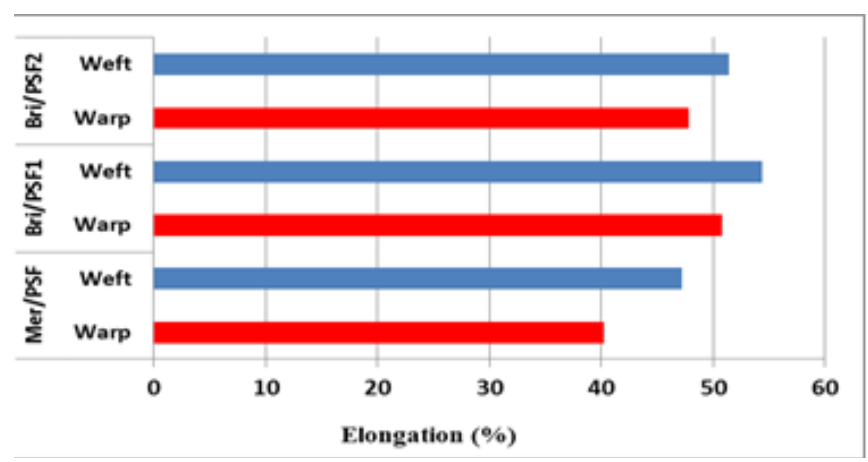

Figure 3: Warp and weft elongation of different produced samples.

Table 4 refers to the significant effects of produced woven samples variables on the tensile strength and elongation properties. It was found highly significant for different blending ratios of produced samples which measured in both warp and weft directions, and interaction between blending ratio with the directions measure of produced samples on the tensile strength test. While there is highly significant for different blending ratios of produced samples, and the directions muse are for elongation test, and we can noted that the increase of polyester ratio had no significant effect on fabric elongation, which presents in the intersection between different blending ratios with directions measure.

Table 4: The significance of different produced samples on tensile strength and elongation.

\begin{tabular}{|c|c|c|c|}
\hline Traits factors & No. & Tensile strength (Kgf) & Elongation (\%) \\
\hline Overall mean & 30 & $89.77 \pm 1.16$ & $48.63 \pm 0.64$ \\
\hline Blending ratios & & $* *$ & $* *$ \\
\hline 1(45Mar:55PSF) $\%$ & 10 & $57.30 \pm 2.00^{\mathrm{a}}$ & $43.7 \pm 1.11^{\mathrm{a}}$ \\
\hline 2(45Bri:55PSF) $\%$ & 10 & $97.90 \pm 2.00^{\mathrm{b}}$ & $49.6 \pm 1.11^{\mathrm{b}}$ \\
\hline 3(45Bri:55PSF) $\%$ & 10 & $114.1 \pm 2.00^{\mathrm{c}}$ & $52.6 \pm 1.11 \mathrm{~b}$ \\
\hline Directions measure & & $* *$ & $* *$ \\
\hline Warp & 15 & $125.53 \pm 1.63^{\mathrm{a}}$ & $46.27 \pm 0.9^{\mathrm{a}}$ \\
\hline Weft & 15 & $54.000 \pm 1.63^{\mathrm{b}}$ & $51.00 \pm 0.9^{\mathrm{b}}$ \\
\hline Bld*Dir & & $* *$ & NS \\
\hline $1 *$ Warp & 5 & $65.00 \pm 2.83^{\mathrm{a}}$ & $40.2 \pm 1.56$ \\
\hline $1 *$ Weft & 5 & $49.60 \pm 2.83^{b}$ & $47.2 \pm 1.56$ \\
\hline $2 *$ Warp & 5 & $144.4 \pm 2.83^{c}$ & $47.8 \pm 1.56$ \\
\hline $2 *$ Weft & 5 & $51.40 \pm 2.83^{\mathrm{b}}$ & $51.4 \pm 1.56$ \\
\hline $3 *$ Warp & 5 & $167.2 \pm 2.83^{\mathrm{d}}$ & $50.8 \pm 1.56$ \\
\hline $3 *$ Weft & 5 & $61.00 \pm 2.83^{\mathrm{a}}$ & $54.4 \pm 1.56$ \\
\hline $\mathrm{R}^{2}$ & \multicolumn{2}{|c|}{0.99} & 0.67 \\
\hline CV\% & \multicolumn{2}{|c|}{7.05} & 7.19 \\
\hline
\end{tabular}


a,b,c,d Within each column, means followed by the same superscript are not significantly different

$$
* * \mathrm{P}<0.01 \text { NS: Non-Significant }
$$

1: Merino/Polyester (45:55)\% 2: Barki/Polyester (45:55)\% 3: Barki/Polyester (30:70)\%

Stiffness property: There is no doubt that; the denier of Barki wool fibers is more than Merino wool fibers (Table 1). From Figure 4 it was seen the stiffness value of Barki/polyester samples gave higher value of stiffness comparing with the produced sample from Merino/polyester, especially for warp direction yarn of fabric. Also, the stiffness values affected with Barki wool ratio in the produced samples, whereas the increasing of Barki wool ratio led to increase the stiffness resistance value for warp direction. In addition high ratio of polyester fibers within the produced samples affected on the stiffness resistance values of weft direction by decreasing. However, there are closely results for the two produced samples of Barki wool in the warp direction yarn of fabrics. That is may be due to plying process of warp direction yarn (Figure 4).

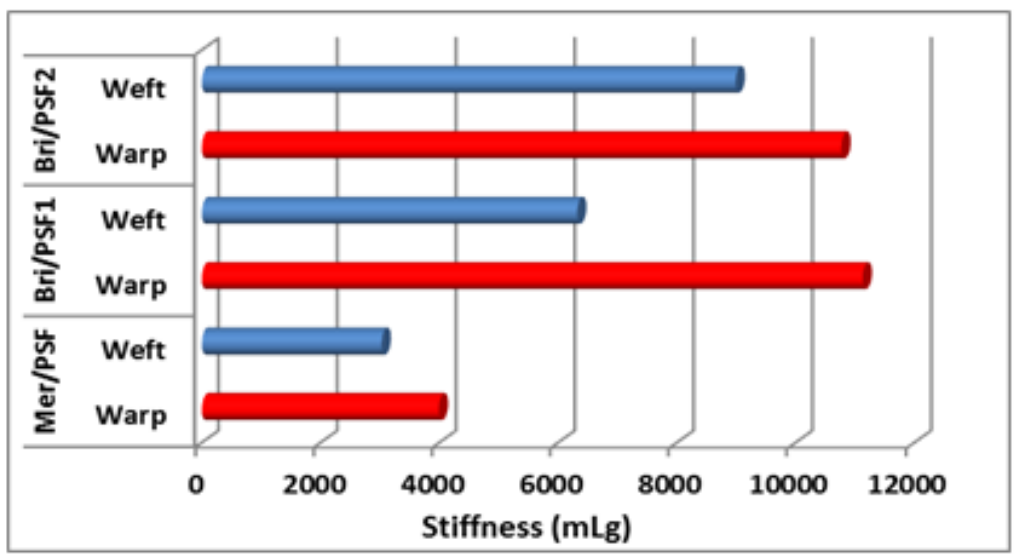

Figure 4: Warp and weft stiffness values for the produced samples.

Abrasion resistance property: Abrasion resistance for produced fabric samples measured related to loss in weight of fabric and its values present in Figure 5. So that, if loss in weight value increases, the abrasion resistance will decrease. The sample produced with Merino/polyester gave the highest value of loss in weight for warp and weft directions compared with the produced samples from Barki/polyester, due to the fineness fibers of polyester and Merino, where they are easy to move from their place within the fabric during the machine's cycles until the occurrence of fabric surface corrosion. While the sample produced from Barki/ polyester (30:70)\% gave the lowest value of weight after abrasion cycles especially for weft direction, this is related to the high ratio of polyester that specified with fine fibers and the yarn count of warp which consist of two yarns twisted together and affecting on the mechanical properties of weft direction. Finally, the samples produced from Barki/polyester (45:55)\% achieved the best results for abrasion resistance by loss in weight for produced fabric, whereas the ratio between the polyester and Barki wool materials reduces the polyester fibers intensification on the fabric surface by the migration of fibers [13], which increase the surface's resistance to friction.

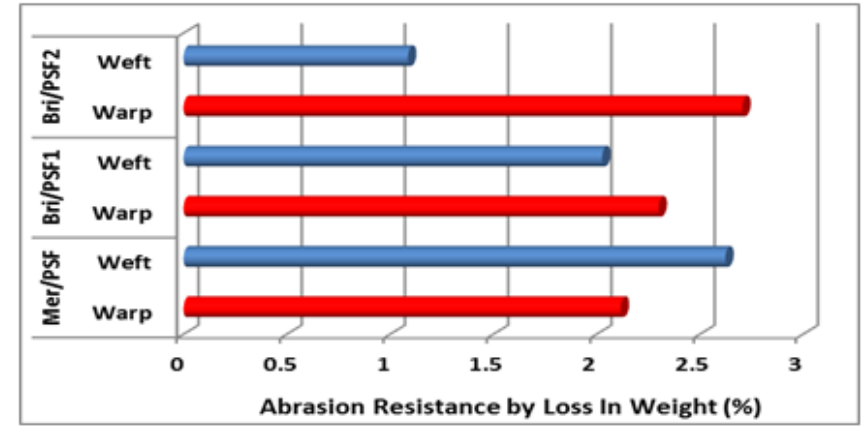

Figure 5: Warp and weft abrasion resistance percentage by loss in weight indication for the produced samples.

Shrinkage resistance property: There are differences between the samples produced from Merino/polyester and the other samples from Barki/ polyester in Figure 6. It was seen that the increasing oh polyester ratio lead to shrinkage resistance especially for warp direction in the samples produced from Barki/polyester $(30: 70) \%$, this due to the polyester which keep on the dimension 
stability and it is also not affected by relative humidity. While the resistance, due to the fineness's fibers of Merino wool as the fine sample produce from Merino/polyester had the highest shrinkage wool has resilience.

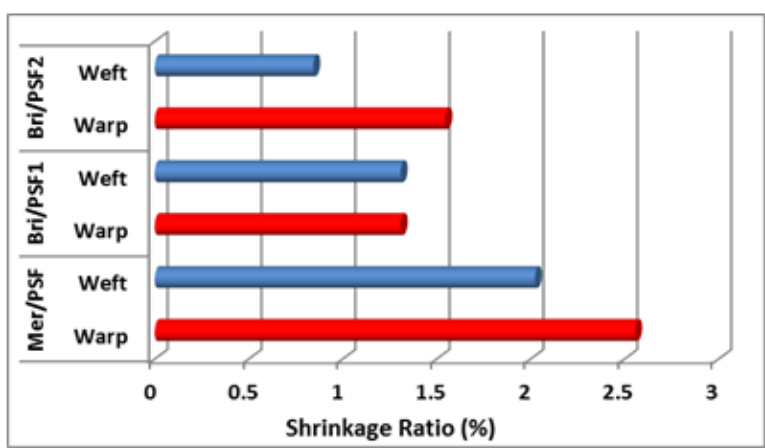

Figure 6: Warp and weft shrinkage ratio for all produced samples.

Table 5 presents the significant effects of produced woven samples variables for the stiffness, shrinkage and abrasion resistance values. There were highly significant for blending ratios of different produced samples which measured in both warp and weft directions on the stiffness resistance results and also interaction between blending ratios with directions measure. While, we can noted the highly significant for the blending ratios of the produced sample for shrinkage resistance property and significant for the results of directions measure, but the interaction between blending ratios with directions measure had non-significant for shrinkage resistance property. Finally; there weren't significant for blending ratios of produced samples which measured in both warp and weft directions on the abrasion resistance results, but there was significant for the interaction between blending ratios with directions measure of produced samples on the abrasion resistance property by indication of loss in weight.

Table 5: Significance of samples variables on stiffness, shrinkage and abration results.

\begin{tabular}{|c|c|c|c|c|c|}
\hline Traits factors & No. & Stiffness (mlg) & Shrinkage ratio (\%) & No. & Abrasion (Loss in weight \%) \\
\hline Overall mean & 24 & $7369.33 \pm 200.06$ & $1.6 \pm 0.10$ & 18 & $2.14 \pm 0.16$ \\
\hline Blending ratios & & $* *$ & $* *$ & & NS \\
\hline 1(45Mar:55PSF) $\%$ & 8 & $3507 \pm 346.59^{a}$ & $2.29 \pm 0.17^{\mathrm{a}}$ & 6 & $2.37 \pm 0.28$ \\
\hline 2(45Bri:55PSF)\% & 8 & $8722 \pm 346.59^{b}$ & $1.31 \pm 0.17^{b}$ & 6 & $2.16 \pm 0.28$ \\
\hline 3(45Bri:55PSF) $\%$ & 8 & $9879 \pm 346.59^{c}$ & $1.19 \pm 0.17^{\mathrm{b}}$ & 6 & $1.90 \pm 0.28$ \\
\hline Directions measure & & $* *$ & $*$ & & NS \\
\hline Warp & 12 & $8627.33 \pm 282.99^{a}$ & $1.80 \pm 0.14^{\mathrm{a}}$ & 9 & $2.37 \pm 0.22$ \\
\hline Weft & 12 & $6111.33 \pm 282.99^{b}$ & $1.39 \pm 0.14^{b}$ & 9 & $1.91 \pm 0.22$ \\
\hline Bld*Dir & & $* *$ & NS & & * \\
\hline $1 *$ Warp & 4 & $3988 \pm 490.16^{\mathrm{a}}$ & $2.56 \pm 0.25$ & 3 & $2.12 \pm 0.39^{\mathrm{ab}}$ \\
\hline $1 *$ Weft & 4 & $3026 \pm 490.16^{\mathrm{a}}$ & $2.02 \pm 0.25$ & 3 & $2.62 \pm 0.39^{a}$ \\
\hline $2 *$ Warp & 4 & $11125 \pm 490.16^{b}$ & $1.31 \pm 0.25$ & 3 & $2.30 \pm 0.39^{\mathrm{a}}$ \\
\hline $2 *$ Weft & 4 & $6319 \pm 490.16^{c}$ & $1.31 \pm 0.25$ & 3 & $2.03 \pm 0.39^{\mathrm{ab}}$ \\
\hline $3 *$ Warp & 4 & $10769 \pm 490.16^{\mathrm{b}}$ & $1.55 \pm 0.25$ & 3 & $2.71 \pm 0.39^{\mathrm{a}}$ \\
\hline $3 *$ Weft & 4 & $8989 \pm 490.16^{d}$ & $0.84 \pm 0.25$ & 3 & $1.09 \pm 0.39^{\mathrm{b}}$ \\
\hline $\mathrm{R}^{2}$ & \multicolumn{2}{|c|}{0.93} & 0.63 & \multicolumn{2}{|r|}{0.48} \\
\hline $\mathrm{CV} \%$ & \multicolumn{2}{|c|}{13.3} & 30.91 & \multicolumn{2}{|r|}{31.44} \\
\hline \multicolumn{6}{|c|}{ a, b,c,d Within each column, means followed by the same superscript are not significantly different } \\
\hline \multicolumn{6}{|c|}{${ }^{* *} \mathrm{P}<0.01,{ }^{*} \mathrm{P}<0.05, \mathrm{NS}$ : Not-Significant } \\
\hline \multicolumn{2}{|c|}{ 1: Merino/Polyester (45:55)\% } & 2: Barki/Polyest & \multicolumn{3}{|c|}{ 3: Barki/Polyester (30:70)\% } \\
\hline
\end{tabular}

Pilling resistance property: Figure 7 refers to pilling resistance values for produced samples. It was found that Merino/ polyester sample achieved the best sample for pilling resistance; this is due to the approximate the diameter measurement between the Merino and polyester fibers. Also, after comparing between two samples which produced from Barki/ polyester, we can see that the increasing polyester ratio in the produced samples led to the decreasing of pilling resistance. Because there are high different diameter between polyester and Barki wool fibers, and the migration behavior of polyester fibers resulting of their lighted 
weight compared to Barki fibers, which has more ability to absorb relative humidity during the test [13] as shown in Figure 8. It was concluded that the previous literature stated that test conditions, yarn structure, content of wool and polyester fibers characteristics affect the pilling property of worsted fabrics [19].

Water permeability property: One of the facts about wool that it has the high ability of absorbs humidity and ambient moisture that reach to $30 \%$ of its weight [20]. So, it was found in figure 9 that the produced sample from Barki/polyester (45:55)\% gave high water permeability rate comparing with other produced sample from (30:70)\% ratio. Also, the Barki/polyester fabric samples absorb high ratio of water related to the produced sample from Merino/polyester which has the same blended ratio of component materials. This is due to the fine wool needs more time to reach the saturated status so it intend to water repellence property, while the coarse wool intends to water permeability may be due to the higher diameter and higher yarn count. Additionally, the fabric structure play main roles in this test, this is depending on the floats of twill structure (Figure 9).

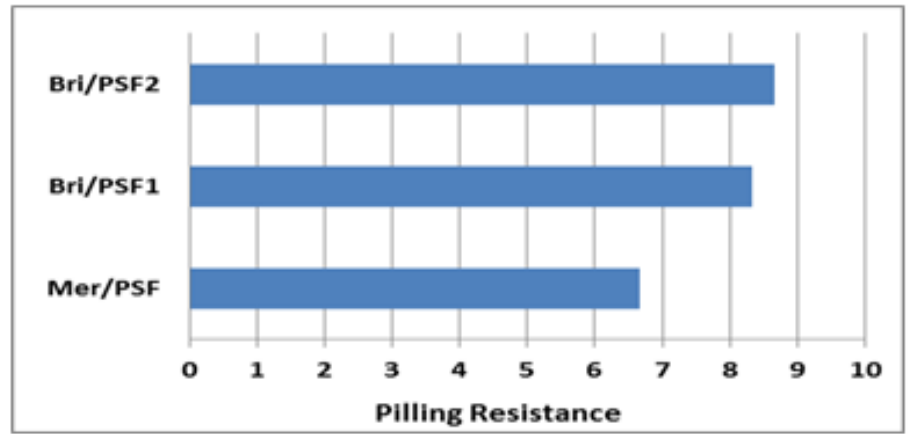

Figure 7: Pilling resistance values by counting in inch ${ }^{2}$ unit for the produced samples.
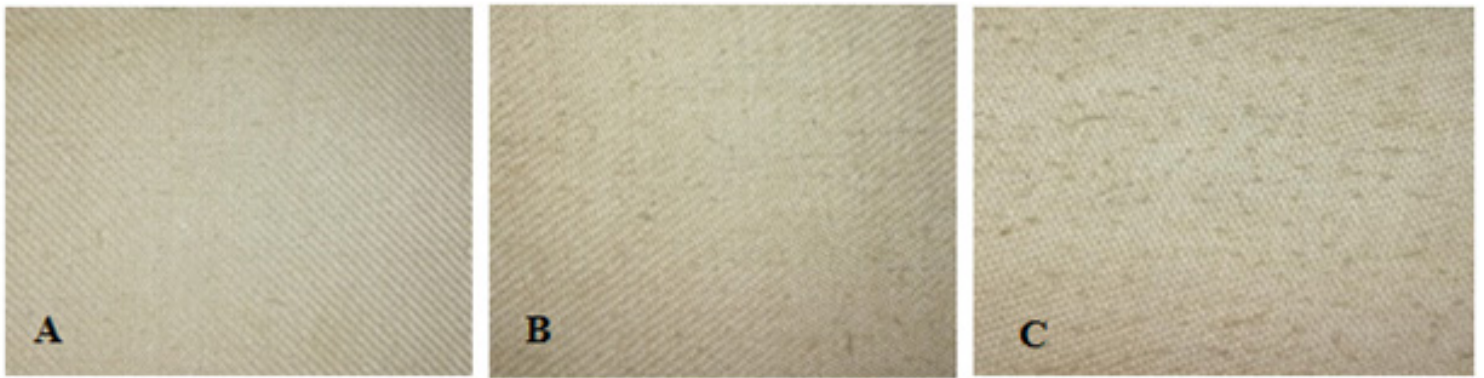

Figure 8: Samples images after pilling test; A: Mer/PSF (45:55)\%, B: Bri/PSF (45:55)\% and C: Bri/PSF (30:70)\%.

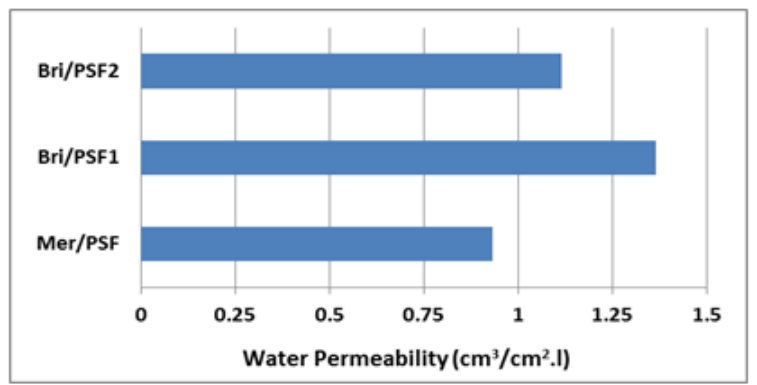

Figure 9: Water permeability ratio for all produced samples.

Air permeability property: Figure 10 shows that the Merino/ polyester sample gave high air permeability value comparing the other produced samples, this due to the fineness fibers of Merino wool and polyester, which merged together and cause the restrain air follow. We can noted that the permeability of air decreases when the wool ratio decrease especially with the samples produced Barki wool, that is may be due to the uniformity in the diameter of polyester fibers, which migrated of the surface fabric during the spinning presses, and cause to restrain the passage of the air during the test compared with different diameter of wool fibers.

Electrostatic properties: Figure 11 shows that the difference in values of electrostatic charges for blended samples from polyester and two types of wool materials that appear on the produced fabric surface. Moreover, all the produced samples carried the negative charge; although the wool material has moderate positive charge, while the polyester has least negative charge [21]. 
The figure also refers to that the Merino/polyester sample had less electrostatic charges on the fabric surface which classified as excellent grade compared to the Barki /polyester samples with the different ratios which classified as fair grade, this is due to that the Barki wool is more rougher and harshness than the Merino wool and generally the coarse wool has irregular distribution of charges on the longitudinal section of fiber [22]. Also, the sample produced from higher ratio of polyester than Barki wool, leads to decrease of the accumulated electrostatic charge on the fabric surface compared to the Braki/polyester (30:70)\% sample, whereas the coarse wool that has high harshness because the surface of the wool is not homogeneous in the density of acidic groups. Although there was no prevalence of acidic groups at the edge of the scales, and Mapping did reveal the presence of positively charged domains near the scale edges. This result would indicate a localized concentration of basic amino acids while may be the remains areas has the negative charges. In spite of this, the wool has discharging of electrostatic very fast that formed on a surface in the moisture saturation state, and its charges is more effective in the dry state [22].

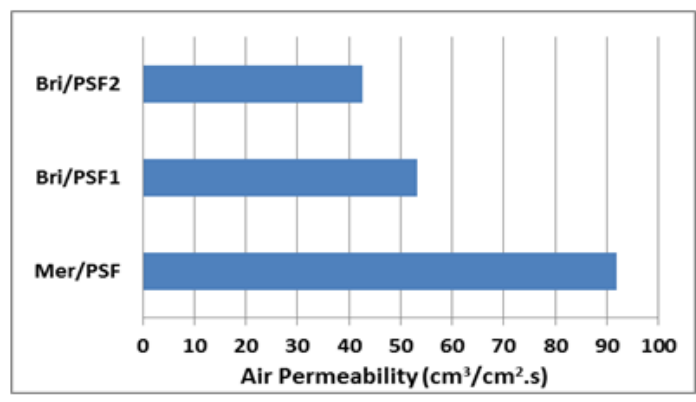

Figure 10: Air permeability ratio for all produced samples.

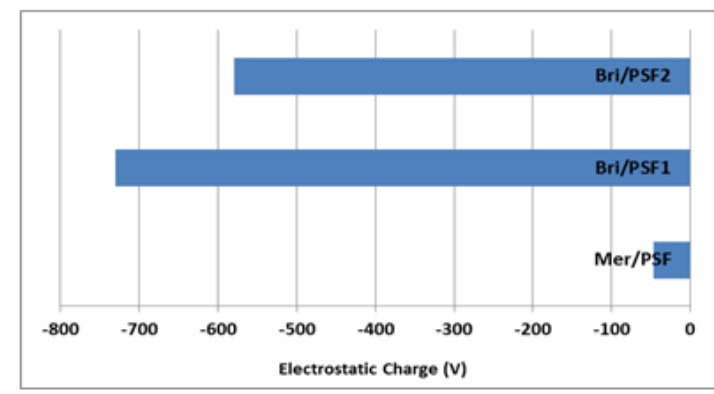

Figure 11: The values of electrostatic charge for all produced samples.

Table 6 shows that the highly significant for difference of blended ratios for the produced samples on the electrostatic charge, air permeability and pilling resistance properties, while there

wasn't significant for difference of blended ratios for the produced samples on the water permeability property.

Table 6: Significance of samples variables on air \&water permeability, electrostatic charge and pilling tests.

\begin{tabular}{|c|c|c|c|c|c|c|c|}
\hline \multirow[t]{2}{*}{ Traits factor } & \multirow[t]{2}{*}{ No. } & $\begin{array}{l}\text { Water permea- } \\
\text { bility }\end{array}$ & Electrostatic charge & \multirow[t]{2}{*}{ No. } & Air permeability & \multirow[t]{2}{*}{ No. } & \multirow{2}{*}{$\begin{array}{l}\text { Pilling resistance } \\
\text { (Unit) }\end{array}$} \\
\hline & & $\left(\mathrm{cm}^{3} / \mathrm{cm}^{2} . \mathrm{I}\right)$ & (V) & & $\left(\mathrm{cm}^{3} / \mathrm{cm}^{2} \cdot \mathrm{s}\right)$ & & \\
\hline Overall mean & 9 & $1.14 \pm 0.09$ & $-453.3 \pm 0.007$ & 15 & $62.53 \pm 3.87$ & 18 & $7.89 \pm 0.23$ \\
\hline Blending ratios & & NS & $* *$ & & $* *$ & & $* *$ \\
\hline 1(45Mar:55PSF)\% & 3 & $0.93 \pm 0.15$ & $-50 \pm 0.01^{\mathrm{a}}$ & 5 & $91.90 \pm 1.23^{\mathrm{a}}$ & 6 & $6.67 \pm 0.39^{\mathrm{a}}$ \\
\hline 2(45Bri:55PSF)\% & 3 & $1.37 \pm 0.15$ & $-730 \pm 0.01^{b}$ & 5 & $53.15 \pm 1.23^{\mathrm{b}}$ & 6 & $8.33 \pm 0.39^{b}$ \\
\hline 3(45Bri:55PSF) $\%$ & 3 & $1.12 \pm 0.15$ & $-580 \pm 0.01^{c}$ & 5 & $42.53 \pm 1.23^{c}$ & 6 & $8.67 \pm 0.39^{\mathrm{b}}$ \\
\hline $\mathrm{R}^{2}$ & 0.41 & & 0.99 & 0.99 & & 0.5 & \\
\hline CV\% & 22.76 & & -4.66 & 4.39 & & 12.25 & \\
\hline \multicolumn{8}{|c|}{ a,b,c Within each column, means followed by the same superscript are not significantly different } \\
\hline \multicolumn{5}{|c|}{$* * \mathrm{P}<0.01$} & \multicolumn{2}{|c|}{ NS: Not- Significant } & \\
\hline & \multicolumn{2}{|c|}{ 1: Merino/Polyester (45:55)\% } & \multicolumn{2}{|c|}{ 2: Barki/Polyester (45:55)\% } & \multicolumn{3}{|c|}{ 3: Barki/Polyester (30:70)\% } \\
\hline
\end{tabular}




\section{Radar chart evaluation}

Figure 12 points to the radar chart for evaluation of produced samples properties. It was found that the (Mer/PFS) sample which weaved from $45 \%$ / of wool blend with $55 \%$ polyester fibers gave the best result of evaluation comparing to the other samples produced.

In addition to; it can be seen that the sample (Bri/PFS) which formed from the same blended ratio of (Mer/PFS) sample appeared the radar curve area very close to the area of (Mer/PFS) sample. So, the samples produced from blended of Barki wool with polyester can be used in many of the usual uses of Merino wool, especially for Barki/Polyester (45:55)\% sample. Therefore, it has shown added properties when blended with a synthetic fibers, and its add value increases.

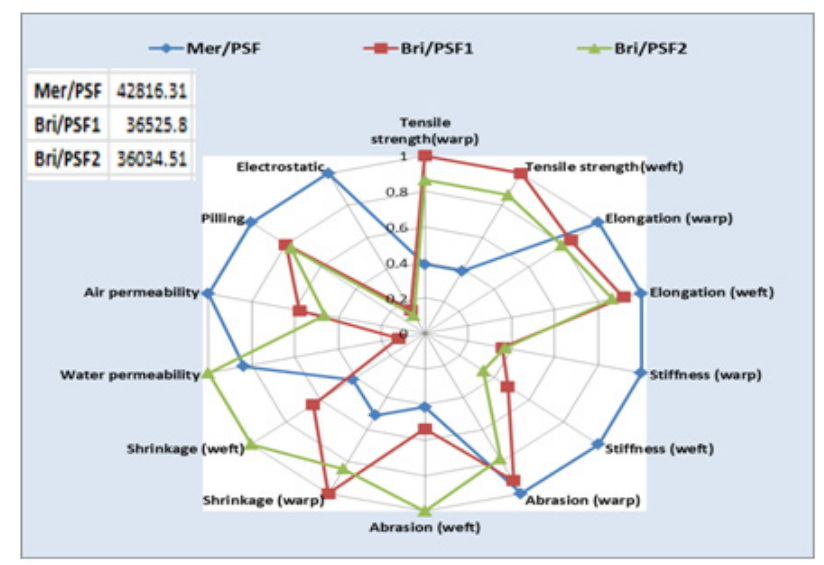

Figure 12: Evaluation of produced samples by area of radar chart.

\section{Conclusion}

The results showed that the mechanical properties were superiority for the samples that made from Barki wool blended with polyester compared to the samples produced from Merino wool blended with polyester with the same ratio between wool and polyester materials.

Otherwise, the Barki wool/polyester with ratio of (45:55)\% has greater values of mechanical properties. While the smoothness was decreases and its surface was intended to the filling effect. Although the samples did not have filling process after weaving, it was seen the clarity of the natural color effect for the samples produced from Barki wool, which increases the aesthetic value of the fabric, also increases the weight per unit due to the high density of local wool and the micron compared to the Merino wool. So, it can use these fabrics to make woman coats.

Produced samples that formed from Merino wool blend with polyester have the good physical characteristics and the wool color is similar to the polyester color.

\section{Acknowledgement}

None.

\section{Conflict of Interest}

Authors declare no conflict of interest.

\section{References}

1. FAOSTAT (2016) Food and Agriculture Organization of the United Nations.
2. Sallam AM (2019) Risk factors and genetic analysis of pre-weaning mortality in Barki lambs. Livestock Science: 230.

3. Ghanem YS (1980) Encyclopaedia of Animal Wealth. Part I: Arab Sheep Breeds, Arab Organization for Education.Culture and Sciences, Arab Centre for the Studies of Arid and Dry Lands. Syria1980.

4. Guirgis RA (1973) Staple length and Kemp as a basis of grading Barki wool. Alex J Agric Res 21(2): 235-240.

5. Gad-Allah AA (2001) Studies on some characteristics, clip preparation and the use Barki wool in the local textile industry. Alexandria University, Alexandria, Egypt.

6. Helal A, GuirgisR A, El-Ganaieny MM (2006) Some hair characteristics of one-humped camels in relation to textile industry. $11^{\text {th }}$ Conference of the International Society of Camelids Research and Development (ISOCARD), Al-Ain, United Arab Emirates.

7. Olga T, Wiah W (2011) Moisture management properties of wool/ polyester and wool/bamboo knitted fabrics for the sportswear base layer. Textile Research Journal 81(6): 621-631.

8. https://colossustex.com/product/blended-yarn-2/

9. (2009) Polyester. Wikipedia.

10. Helal A, Agamy R, Gad- Allah AA, Al Betar EM, Mahouda SF, et al. (2019) Effect of a Subjective Grading System and Blending with Polyester on Selected Wool and Yarn Characteristics of Subtropical Egyptian Barki Sheep. Fibers\& Textiles in Eastern Europe 27(137): 23-27.

11.(2006) What is merino wool. Wool X Hernio.

12. Hamish (2007) Why Merino wool and what makes it so special.

13. Elshakankery MH (2008) Pilling resistance of blended polyester/wool fabrics. $1^{\text {st }}$ international conference of textile research division, NRC, Cairo, Egypt: 253-259.

14. Hakeim OA, El Zawahry MM, Aly NM, El-Hawary NS, Diab HA, et al. (2015) Anti-Static and Functional Properties of Asminosilsesquioxane Oligomer Treated and Dyed Fabrics. Journal of the Textile Association: 90-101. 


\section{SAS (2001) Statistics Version 5. SAS Institute Inc., Cart, NC., USA.}

16. Duncan DB (1955) Multiple ranges and multiple F-tests. Biometrics 11 $1-42$.

17. Abdel-Fattah SH, El-KatibE M (2007) Improvement of Pilling Properties of Polyester/wool Blended Fabrics.Journal of Applied Sciences Research 3(10): 1206-1209.

18. Sule AD, Gurudatt K (2001) Polyester- Cellulose Fabrics and Pilling Performance. The Indian Textile Journal 111(8).
19. Long L, Wei Z (2004) Pilling of polyester/wool blends. Indian Journal of Fibre \& Textile Research 29: 480-482.

20. Lin HT, Xu L, Jiang F (2013) Study of moisture absorption property of the wool with different finesse.

21. Kurtus R (2018) Materials that Cause Static Electricity.

22. Bonnie Z, James C, Abbott AG, Ellison MS, Kennedy MS, et al. (2011) Variation of Surface Charge along the Surface of Wool Fibers Assessed by High-Resolution Force Spectroscopy. J Eng Fiber Fabric 6(2): 61-66. 